$\mathrm{RC}$

628

F85s

FRANZ

A $\quad$ STUDIES OF

FEELLE-MIUDEDIESS

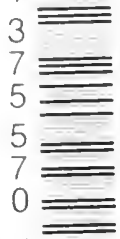

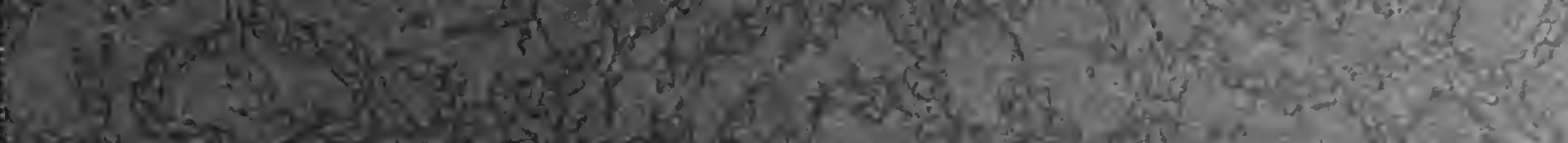

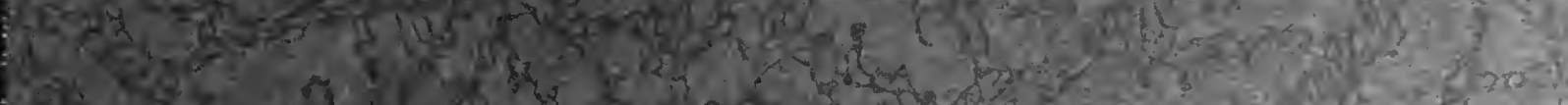

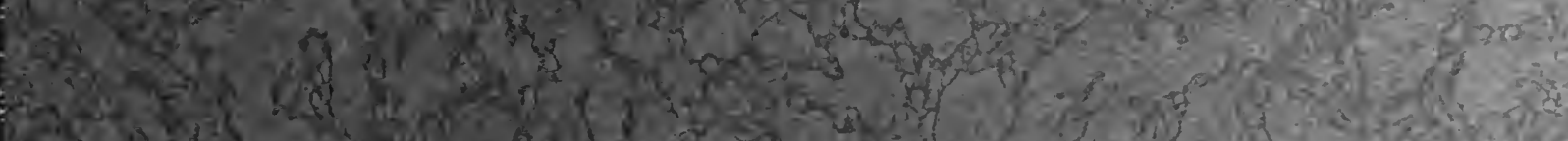

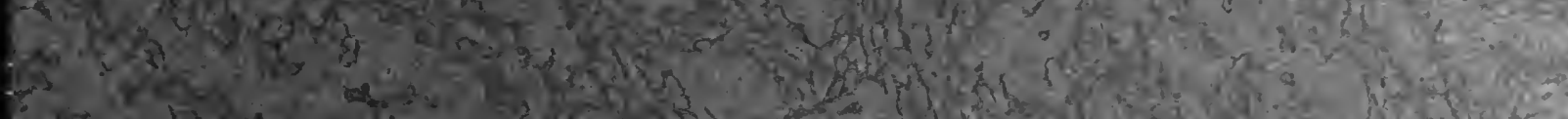

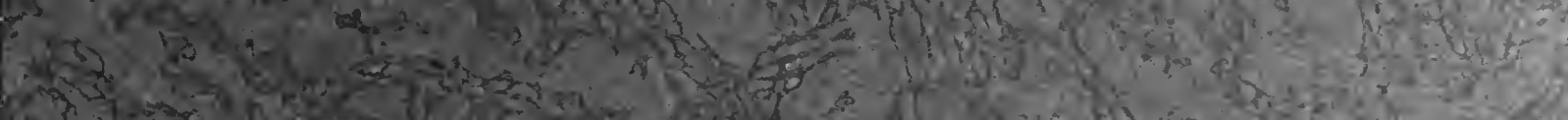
(6)

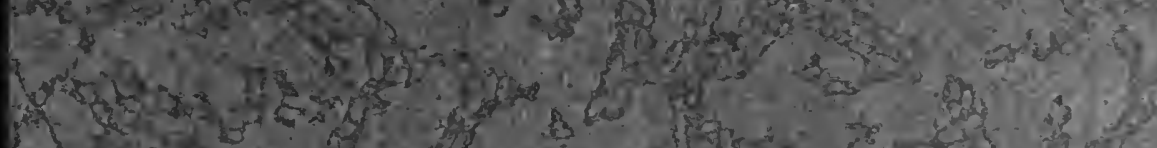
(1)

If

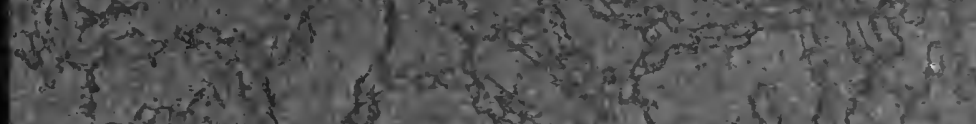

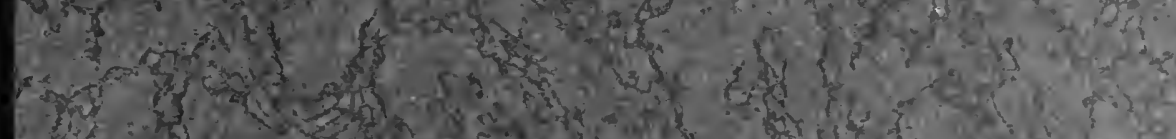




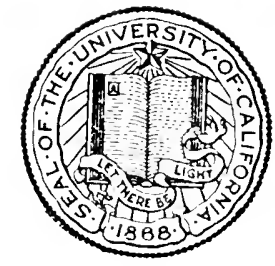 \\ THE LIBRARY OF \\ THE UNIVERSITY OF CALIFORNIA LOS ANGELES}




\section{STUDIF; OF FEEBLE-MINDEDNESS}

BY SHEPHERD IVORY FRANZ

Reprinted from The Journal of Philosophy, Psychology and Scientific Methods, Vol. II., No. 11, May 25, 1905.

\section{UNIVRRSITY OF CALIFORNIA \\ AT \\ LOS ANGELES \\ LIBRARX}




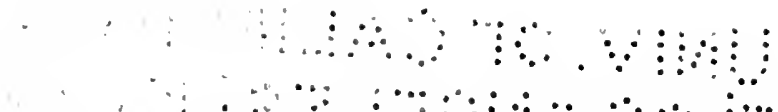

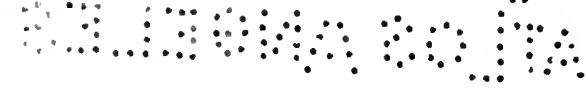




\section{REVIEWS AND ABSTRACTS OF LITERATURE}

\section{Studies of Feeble-Mindedness. ${ }^{2}$}

The study of the mentally defective classes is of interest and importance to both physicians and psychologists. Unfortunately, however, psychologists have concerned themselves almost wholly with the investigation of the mental processes of normal people, and have not considered the subject of abnormal psychology. Physicians, on the other hand, are interested in abnormal psychology, but largely, and almost exclusively, in those mental processes which are of importance for diagnosis, and those

${ }^{1}$ Under this title there have been included the following articles on idiots, imbeciles, enfants arrièrés, enfants faibles d'esprit, and on enfants anormaux and abnormal children when it was evident that the term 'abnormal' was used synonymously, or nearly so, with 'feeble-minded ':

1. 'Les enfants anormaux a Bruxelles.' DeMoor ET DANIEx. Année psychologique, 1900, VII., 296-313.

2. 'Experiences de copie: essai d'application a l'examen des enfants arrièrés.' Simon. Ibid., pp. 490-518.

3. 'L'interprétation des sensations tactiles chez les enfants arrierés.' Srmos. Ibid., pp. 537-558.

4. 'Eine experimentelle Studie über die Association in einem Falle von Idiotie.' A. Wreschner. Allg. Zeitsch. f. Psychiatrie, 1900, LVII., 241-339. (Complete account of association experiments. Prolix but good in giving material for comparison.)

5. 'Taste and Reaction Time of the Feeble-Minded.' A. R. T. WrLIE. Journal of Psycho-Asthenics, 1900, IV., 109-112.

6. 'Study of the Senses of the Feeble-Minded.' A. R. T. WrLIE. Ibid., pp. 137-150.

7. 'Memory of the Feeble-Minded.' A. R. T. WrIIE. Ibid., 1900, V., 16-24.

8. 'Motor Ability and Control of the Feeble-Minded.' A. R. T. Wrutr. Ibid., pp. 52-58.

9. "L'illusion de poids chez les anormaux et le 'Signe de Demoor." E. Claparìde. Arch. de Psychol., 1903, II., 22-32.

10. 'La mesure de l'attention chez les enfants faibles d'esprit (phrenastheniques).' F. Corsoni. Ibid., pp. 209-252. (Good material but not sufficient work on normal children for comparison. Esthesiometric results not checked by other methods.)

11. ' Notes sur la psychologie des enfants arrierés.' T. JonckneEre. Ibid., pp. 253-268.

12. 'Psychophysical Tests of Normal and Abnormal Children.' R. L. KerLr. Psychol. Review, 1903, X., 345-372. (Incomplete and evidently hasty work. Not sufficient account of methods for purposes of confirmation. Subjects not described.)

13. 'Experimental Studies in Mental Deficiency: Three cases of Imbecility (Mongolian) and six cases of Feeble-mindedness.' F. KuHLMasx. Amer. Jour. of Psychol., 1904, XV., 391-446. (Excellent article. Material well digested. Good bibliography.)

14, 15. 'Ueber die Assoziationen von Imbezillen und Idioten.' K. WEHRIN. Jour. f. Psychol. u. Neurol., 1904, 1V., 120-123, 129-143. (Confirmation and extension of Wreschner's work. Many cases.)

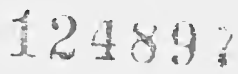


which help in making prognoses. What information we have, therefore, is meager in amount and, perhaps, as is sometimes said, superficial. Many interesting mental phenomena are noted and explained in an offhand way, and many have not been noted, because they are thought to be of little diagnostic or prognostic importance. The conditions which have been studied only superficially and those which have not been studied are likely to throw light upon similar but elusive processes in normal people. Much valuable information could be obtained from a study not only of the defects, but also of the exaggerations and the inconsistencies in the insane and feeble-minded.

The possible difficulties of experimentation upon the insane and the mentally deficient may have kept some psychologists from attempting investigations. It may be said, however, that the difficulties have been greatly exaggerated, and such difficulties as there are may be readily surmounted. Opportunity for the careful and systematic study of patients may be obtained readily at many hospitals. Whatever former disinclination to the study of patients by 'outsiders' medical men may have had has given place to a willingness to have careful experiments made to obtain a better knowledge of the psychical conditions in the mentally abnormal. The studies which are reported in this review indicate clearly that it is considered necessary to have gencral observations, such as are given by Sollier, ${ }^{2}$ analyzed, supplemented and verified by a careful study of cases by experimental methods.

The feeble-minded have been classified according to many different criteria-speech, moral and intellectual capacity and dullness, extent of mental faculties and attention-and the names designating the conditions have widely differed. Dagonet makes four classes: (1) Simple-minded, (2) imbecility, (3) idiocy, (4) automatism. [Voisin has used the term 'mental debility' in about the same sense as Dagonet's 'simple-minded.' Sollier, who bases his classification upon the process of attention, divides the feeble-minded into three classes only: " (1) Absolute idiocy, a complete absence and impossibility of attention; (2) simple idiocy, a feebleness and difficulty of attention; (3) imbecility, instability of attention." * In all classes Sollier says there is not only a diminution in quantity, but also a modification in quality of the mental faculties. Moreover, it may be added, all idiots present cerebral lesions and are thus further differentiated from normal people and imbeciles.

1. Sensation.-Several authors have cited the disturbances and aberrations of sensation as the cause of the lack of mental ability in some of the feeble-minded. It is undoubtedly true, as has been pointed out, that the absence or alteration of sense organs prevents the associational processes ordinarily concerned with these spheres, and to that extent there is a defect of the mental life. Blindness or deafness or the lack of other senses, or a combination of two or more defects in one person, does not necessarily produce an incapacity for the associations in other sensory motor paths. Sensory defects may contribute to, but they are probably

' 'Psyehologie de l'idiot et de l'imbecile,' 2d edit., Paris, 1901.

${ }^{3}$ Op. cit., p. 17. 
not the greatest and certainly not the only factors in, the production of mental weakness.

Most idiots, Schleich found, are hypermetropic, while in normal children there is a tendency to myopia. Wylie (6) ${ }^{4}$ found in the children examined by him a visual dullness six to eight times the normal, and Kelly (12) in the pupils of the Physiological School (who are not described, but who are probably imbeciles), found poor vision. One half were below the standard of keenness, and there was astigmatism in all but one or two. On the other hand, Sollier makes the general statement that 'in imbeciles hearing as well as sight presents nothing abnormal.' Schleich has defined the abnormality in the feeble-minded, but from the articles by Wylie and by Kelly it is impossible to tell what the differences are.

Owing to the incomplete color vocabulary of many idiots and imbeciles it is difficult to make determinations of the color sense. Jonckheere (11) and Kelly (12) agree that often color vision is defective. Kelly reports six out of twelve children with some kind of color blindness and one with total color blindness. Only two of Kelly's cases had an accurate color rocabulary, and the same deficiency has been noted by Jonckheere. Furthermore, Jonckheere states that in these cases it is very difficult to develop the sense (terminology).

Only two cases in the Physiological School were found to have normal hearing (12), but in other places nothing abnormal has been found ( 6 and Sollier, see above).

Taste and smell are very often dulled or perverted in the feebleminded. The general statement is made that simple idiots are voracious and gluttonous, and that imbeciles are nearly all gourmands. Idiots will carry to their mouths anything which comes to hand-just as very many normal children do-but, in addition, some will eat salt as if it were sugar. Stones, earth, sticks, bugs and even excrement are swallowed by those in whom taste is lacking or perverted. Of 66 children examined by solutions of quinine, acid and salt, 23 could not tell any difference, 16 responded to the bitter, 40 to acid and 22 to salt. Twenty of the brightest children averaged for threshold-sugar, 1.3 per cent. solution; salt 0.48 per cent.; acid, 0.41 per cent.; quinine, 0.0177 per cent. (5).

The pain threshold is higher than in normal children ( 6 and 12), temperature threshold higher (12), touch dulled (6) and the double point threshold of touch increased ( 3 and 12), while the muscle sense is unusually bad (6 and 11). Wylie (6) found a dullness of the muscle sense varying according to the general mental ability, and because of its importance in the education of the feeble-minded efforts are now being made towards a thorough training in this field.

Demoor (1) has found and Claparède (9) has confirmed a reversal of an ordinary weight illusion in cases of idiotism. When two masses of unequal size, but of equal weights, are lifted, the smaller is judged the heavier. This illusion is found in children from the age of six or seven and is constant throughout life in normal people, but in lower grades of

- These numbers refer to the numbers of the articles quoted in note 1 . 
idiotism a reverse judgment is given constantly in some cases, and in others the illusion is absent. The reverse illusion-called the 'sign of Demoor' - is found in those cases which are incapable of education, and it has been suggested as a means of diagnosis of idiotism in its worst form. Claparède concludes from his study that "the presence of the weight illusion does not mean that the feeble-minded are of a teachable type, but the 'sign of Demoor,' when present, speaks strongly in favor of idiotism."

2. Motor Ability and Fatigue.-Motor training is the kind of education to which most of the feeble-minded readily respond, and upon which depends much of their other teaching. If the movements are rapid and accurate and under fair degree of control much may be hoped for in any attempt to improve their condition. Considerable attention has been devoted, therefore, to the study of motor ability, particularly in relation to school work in the hospitals.

Strength and steadiness (8), accuracy and rapidity of movement (12 and 13) are all less than in normal children, and the threshold of movement is larger (12). Experiments similar to those made by Fullerton and Cattell ${ }^{\mathrm{s}}$ on the accuracy of perception of the extent of movement in 34 children of the Minnesota School showed no appreciable deviation from the normal (although the author concludes that there is an error of 2 to 10 times the normal) (7): All the experimenters found a very

$\begin{array}{llr} & \text { wylie } & \text { F. and C. } \\ 100 \mathrm{~mm} . & +8 & +11.8 \\ 300 \mathrm{~mm} . & -1 & +2.8 \\ 500 \mathrm{~mm} . & -17 & +4.3 \\ 700 \mathrm{~mm} . & & -4.8\end{array}$

It must be remembered that W.'s results are obtained from children, and that perhaps the $500 \mathrm{~mm}$. experiments would give effects similar to those found by F. and C. for $700 \mathrm{~mm}$.

slow rate of tapping and arm movement (8,12 and 13). Kuhlmann (13) obtained results of practice in accuracy,-throwing at a target,- -but the curve is not regular, and showed a decrease in ability so that occasionally it dropped to a point below which it had started. This is undoubtedly due, as the author points out, to decreasing interest; but when the interest is again aroused, as was done, the curve rises again.

The experiments on tapping-most rapid and continued movementswere examined for evidence of fatigue. Many of the subjects tapped at a very slow but continued speed throughout the experiments, and it was difficult, sometimes impossible, to make them tap at a faster rate. The average maximum rate is very slightly above the normal rate. Some tapped faster at first and gradually decreased in rapidity, but neither Wylie (7) nor Kuhlmann (13) believes the decrease to be due to fatigue. Kelly attributes the result to a rapid fatigue, but disregards certain results. Of the children examined by him three showed an increase in

" Perception of Small Differences.'

- The errors from Wylie's scries and those obtained by Fullerton and Cattell (p. 48) are as follows. 
tapping with the finger from the first to the last parts of the experiment, and four showed corresponding increases in rapidity with arm movements (12). The results would not lead one to believe that ' fatigue with backward children, as would be expected from their low vitality, is very rapid and considerable' (Kelly, 12), but rather that 'the lowering of interest and attention does not permit deduction regarding fatigue (Kuhlmann, 13).

3. Attention.-Most authorities agree that the lack of attention is the most common defect in the feeble-minded and the greatest hindrance to their education. If the attention can be sufficiently aroused and trained it is probable that other deficiencies will give place to a more normal condition. Since this matter is considered of such importance we should expect much time given it in the experimental determination of the condition in imbeciles and idiots, but, unfortunately, few of the experimental studies consider the subject.

The results of the experiments upon motor ability and fatigue reported above give some indication of the extent of the attention. Kublmann (13) compared the maximal and the normal rate of tapping, and found an average increase of only $1 \frac{1}{2}$ taps per second when the attention was directed to make movements as rapidly as possible. (One subject showed a decrease in rate, and another gave practically the same results in both sets of experiments.) The maximum rate is much slower than in normal children. When the subjects were told to tap in time with the beat of a metronome, the accuracy was much greater during the first half minute than at any later time. It seems evident, therefore, that the attention was kept up for about 30 seconds. The esthesiometric tests of Consoni (10) show, in a uniformity of the double-point threshold, a considerable degree of attention to stimuli of one kind, but when distracting influences were brought in-lights, counting blows on the other hand, counting the beats of a metronome, odors, tasting solutions, etc.-the threshold was much greater and much more varied than in normal children. The alterations in attention were found more prominent in the phrenasthenics of the most marked type. Consoni appears to agree with Sollier ${ }^{\mathrm{T}}$ in his conclusion: the degree of general capacity of attention is in direct relation to the power of inhibition, and the examination of the attention furnishes a precise means for the estimation of the degree of mental weakness.

4. Reaction Times.-Twenty-two children gave an average of $.388 \mathrm{sec}$. (M. V., .08) for touch reaction, 21 experiments each; and sixteen children, for sound, averaged .293 sec. (M. V., .085), 24 experiments each. Eight Mongolian type averaged .396 sec. for touch (M. V., .095), and .360 sec. for sound (MY. V., .113) (5). The individual averages and variations are not recorded, and it is impossible to tell how much variation there is in the group, and how large the individual variation is. Wylie concludes, however, from the experiments that 'long reaction times and high mean variations seem to be characteristic' of the feeble-minded.

In his experiments on association Wehrlin noted the time for giving the

'Op. cit. 
associations in one high-grade idiot and four imbeciles. One subject was found to give reactions as rapidly as normal people, but the other four were very slow. The average time in seconds for the associations to concrete words was found to be 3.4 sec., normal subjects 1.8 sec.; to abstract words, 3.7 and 1.9 sec., respectively; to adjectives, 3.5 scc. and 1.9 sec.; and to verbs, $3.3 \mathrm{sec}$. and $2.2 \mathrm{sec}$. (14 and 15). Wreschner has in one subject the times of about 1,000 association reactions, but these have not been calculated in a manner that makes them available (4). The average time in his experiments is about 3 seconds. The naming of ten object pictures, the distributing cards of different kinds, etc., were used to determine the time for discrimination, association and morement in the subjects examined by Kuhlmann (13). For naming a picture and distributing a picture card Kuhlmann found an average time of 1.48 and 1.46 sec., respectively. For distributing colored cards, 1.67 sec., and for form cards $1.93 \mathrm{sec}$. The general average for the discrimination, association and movement for one card is $1.64 \mathrm{sec}$. In addition, the author made separate tests of discrimination time with dominoes, in which experiments the time was very long. No direct comparison is given for normal children.

5. Association and Memory.-As was to be expected, the associations of idiots and imbeciles are simple and not very varied. Wreschner (4) used as stimulus words, (a) adjectives descriptive of light and color, form and direction, movement, touch, temperature, hearing, smell, taste, pain and general sensations, and esthetic feelings; $(b)$ nouns-parts of the body, objects in a room, in a house, in a city, in the earth, botanical words, names of animals, members of a family, and occupations; (c) abstract words-with cheerful and sorrowful idea content, descriptions of feelings, will, understanding and consciousness, legal conditions and interjections. These words were used as stimuli ten times each. The associated words which were given are noted in detail and the time in seconds for each association. These are grouped, classified and analyzed in detail. One is struck with the persistence of certain associations throughout the series of ten, and with the fact that there are so many purely sound associations. $\mathrm{He}$ finds that the relative number of sound associations for adjectives is 1:3.8; for concrete words, 1:0.7, and for abstract words, 1:0.4. The content associations take a longer time than the sound association, and this is particularly noticeable if the sound and content associations for the same stimulus words are considered. Only one case was tested by Wreschner, viz., an idiot. Wehrlin experimented on 13 idiots and imbeciles-average age, 40 - with 58 to 290 experiments each. The simple character of the 'associations' is evidenced by the following list of kinds of associations which were given (14 and 15).

1. Tendency to definition: e. g., 'year'-' 12 months.'

2. Tautology: e. g., 'run' —' a man runs '; ' hair'_'beautiful hair.'

3. Generalization: e. g., 'bread '_' eatable.'

4. Time, origin, use, etc., characterization: e.g., 'book'-' for reading.'

5. General functions: e. g., 'wood '-' it burns'; 'bird '- 'it flies.'

6. Examples and reminiscences: e. g., 'sick'-'I was sick'; 'father' - he threw me down stairs once.' 
Probably in no other single aspect of mental activity of the feebleminded are there so varied differences as in memory. II Many are unable to remember the simplest words, while others have remarkable memories for special things, e. g., calculation, playing musical instruments, etc. Jonckheere (11) reports two cases of remarkable memory. An imbecile boy examined by him could recognize and name in French or German the disks for a music box with which he played, although he could not read. In this case there was a memory of the arrangement of holes in the disk, or probably of the design of the inscription. Another fecble-minded boy, who entered the school at the age of $9 \frac{1}{2}$ with only a German vocabulary, learned in $3 \frac{1}{2}$ years French and the Flemish patois and can recite in Dutch. Many of the children of the Vaucluse School have been found to compare favorably with normal children in their memory for numbers and words (copying 50 figures and two sentences); but idiots and imbeciles do poorly in all three tests (2).

Four numerals can be immediately repeated by many feeble-minded, and some can give five or six (12). Wylie tested the visual memory by having children pick out 5 cards (containing colors, letters or forms) previously shown to them, from a number, with the following average results : form, 2.4 cards recognized; color, 2.4; letters, 2.6 (7). Similar results were obtained by Kuhlmann (13). The auditory memory was tested by repetition of six associated words, repetition of groups of sentences, and selection of five nonsense syllables, with the following results: average number of words given correctly, 3.8 ; words in sentences, 11; nonsense syllables, 2.1 .

6. Miscellaneous Observations.-All authors agree that the notions of time and space are very difficult to teach the feeble-minded (Sollier, Demoor and Daniel, and Jonckheere). Time is much more difficult than space, and past time much harder than future (11).

Like other mentally underdeveloped people, bright colors are most often preferred. Music with its rhythm has a wonderfully dynamogenic effect, and in some schools it is being used, with excellent results, in classes for gymnastics and motor training.

McLean Hospital for the INsaye,

Shepherd Ivory Franz.

Waverley, Mass.

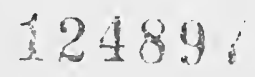




This book is DUE on the last date stamped below

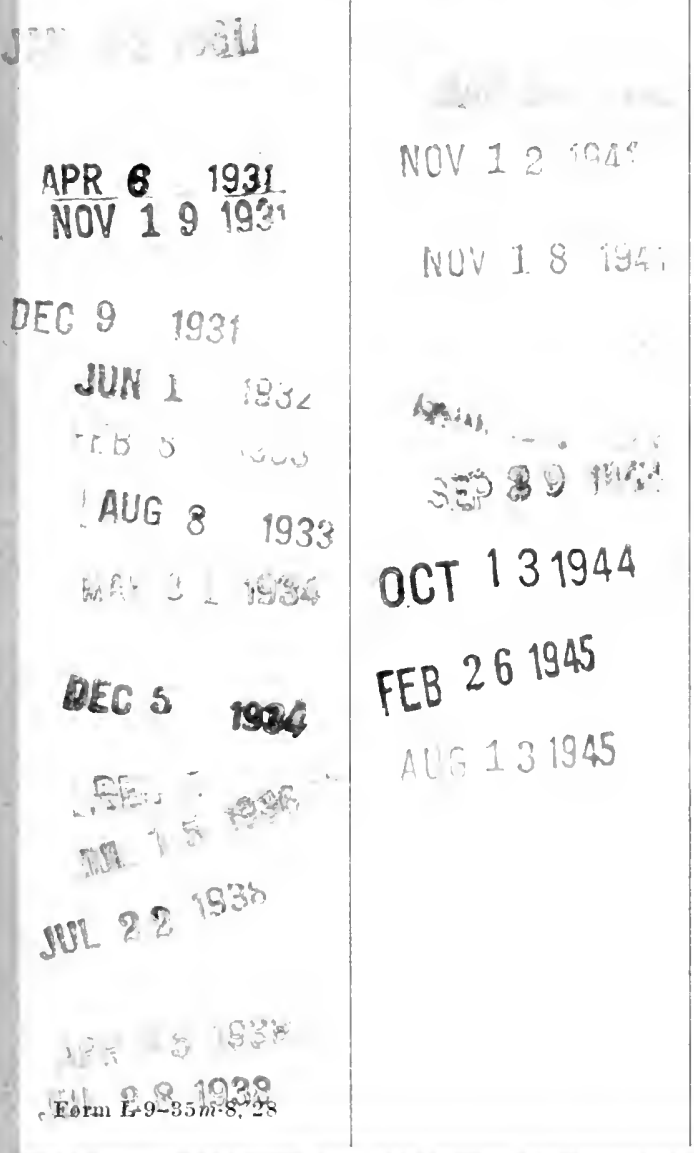

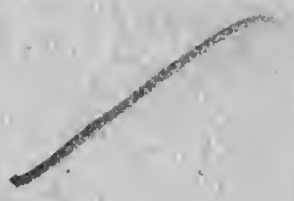

ENTVERSITE Of OALUORNHA AT 


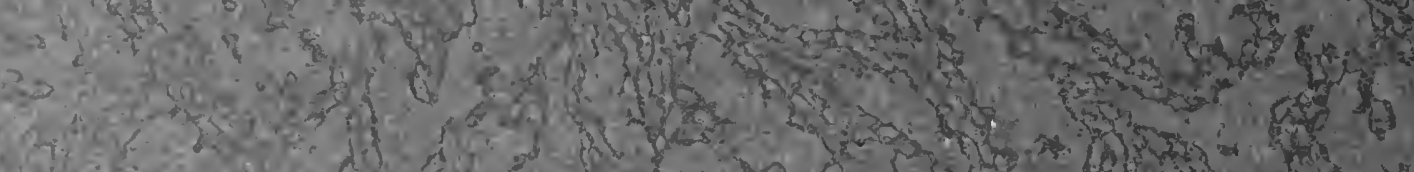

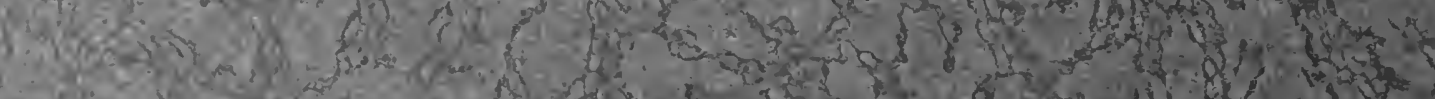

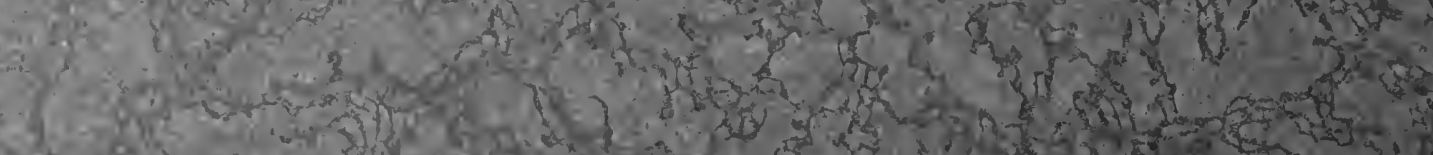

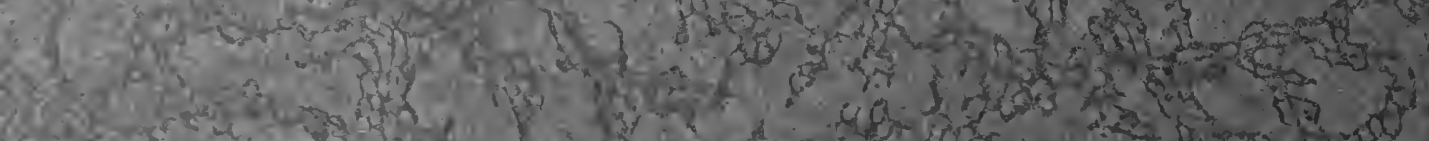

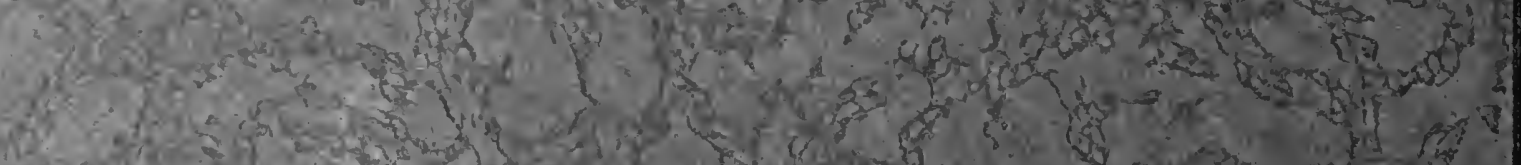
W0.

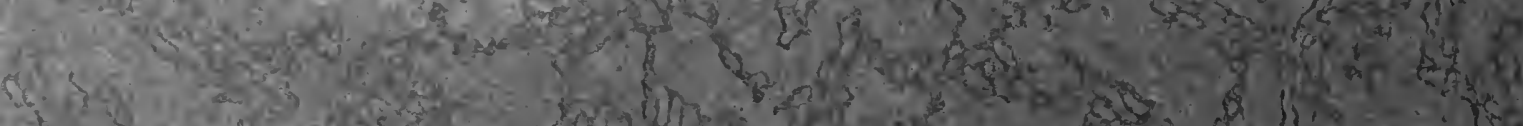
2.

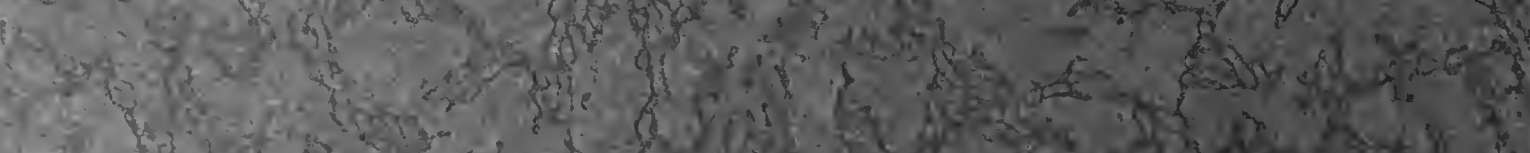
ats

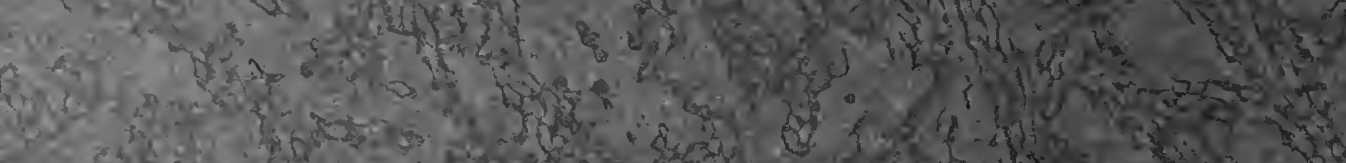

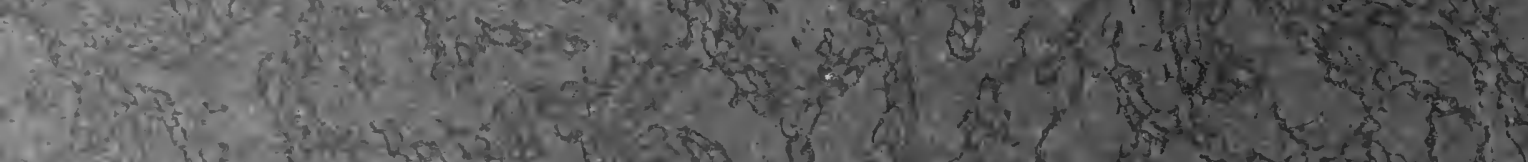

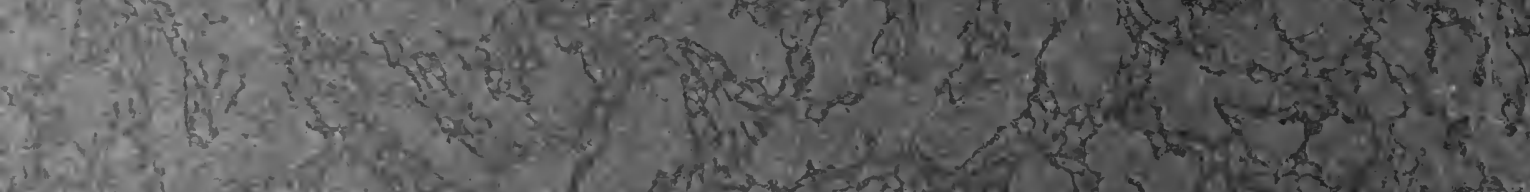

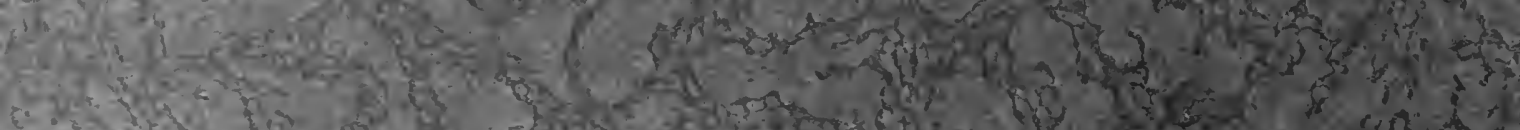

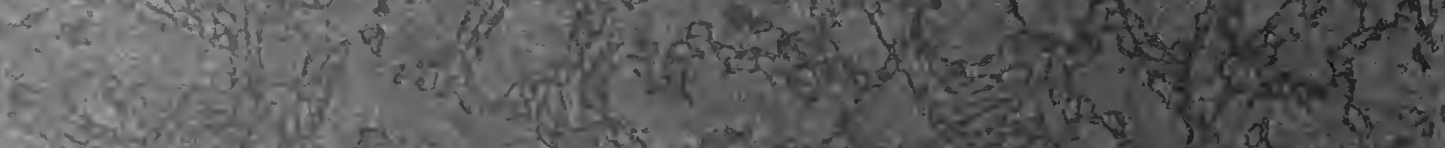

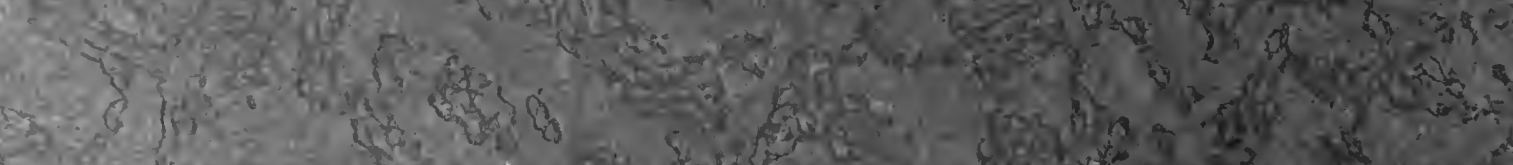

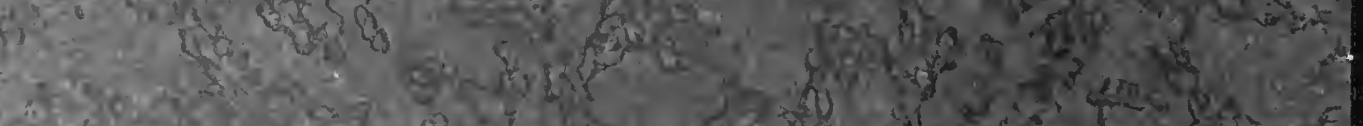
35
75

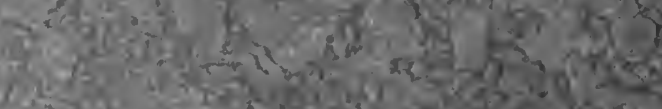

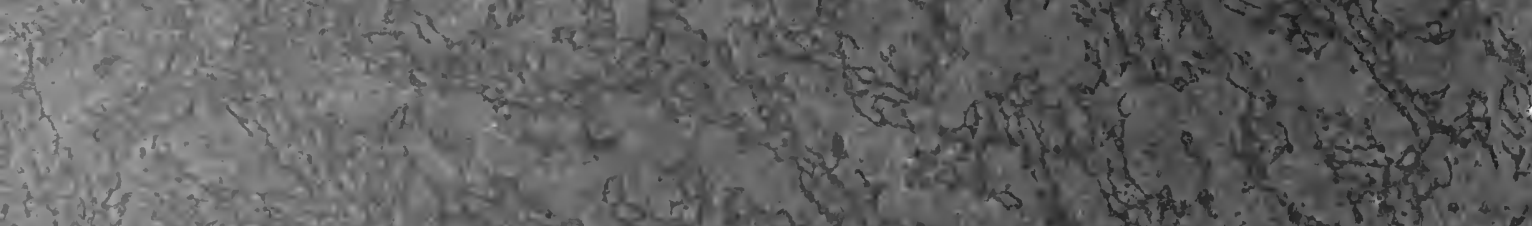

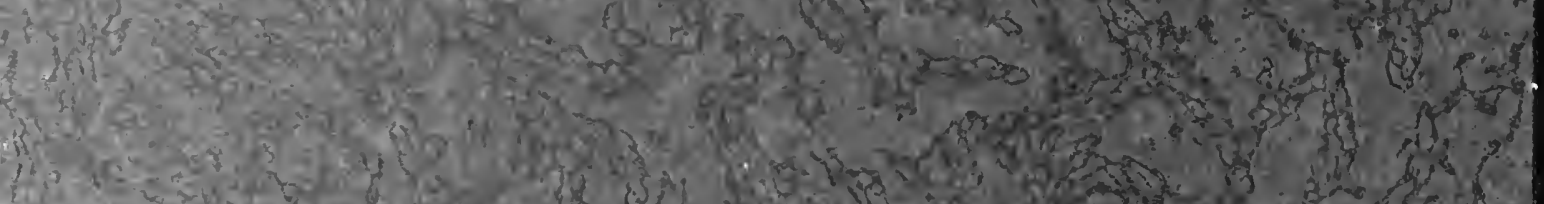

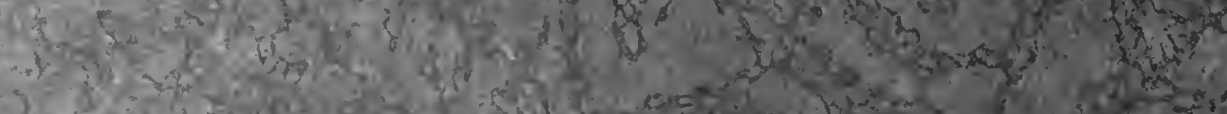

